\title{
El Centro de Arqueología Subacuática de Cataluña
}

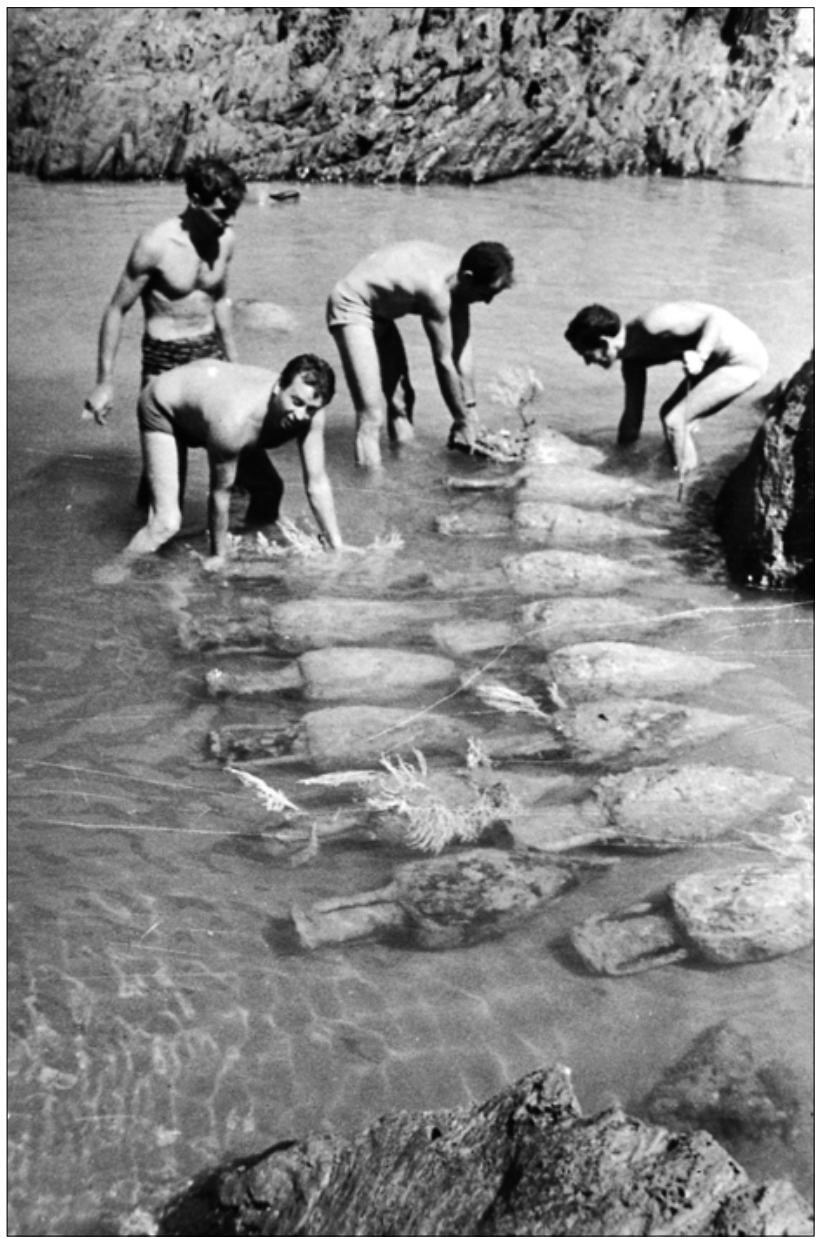

Recuperación incontrolada, en los años 70, del cargamento de un barco

\section{Xavier Nieto}

Director del Centre d'Arqueologia Subaquàtica de Catalunya

\section{Resumen}

Los orígenes del Centre d'Arqueología Subaquàtica de Catalunya (CASC) vienen marcados por tres hitos destacables: la celebración en Barcelona, en 1961, del III Congreso Internacional de Arqueología Subacuática, la constitución en 1972 del Patronato de Arqueología Subacuática de Gerona y la creación en 1981, por parte de la Diputación de Gerona, de un departamento dedicado específicamente a la arqueología subacuática.

En 1992 nace el Centre d'Arqueología Subaquàtica de Catalunya con unas funciones orientadas al in- ventario, la protección, la conservación, el estudio y la difusión del patrimonio arqueológico de Cataluña que se encuentra sumergido en aguas costeras e interiores.

Para el CASC la arqueología subacuática no se estructura como una actividad independiente de la arqueología terrestre, sino todo lo contrario se potencia una íntima relación entre ambas.

EI CASC realiza, fundamentalmente, dos tipos de trabajo: la Gestión del patrimonio cultural subacuático de Cataluña y la investigación científica de dicho patrimonio.

\section{Palabras claves}

CASC / Catalunya / Arqueología subacuática / Investigación / Protección / Conservación / Difusión 
El 6 de noviembre de 1992 se publicaba en el Diario Oficial de la Generalitat de Catalunya el decreto 237/1992 de 13 de octubre por el que se creaba el Centre d'Arqueologia Subaquàtica de Catalunya. Es un texto escueto en el que se establece que las funciones de este centro son: El inventario, la protección, la conservación, el estudio y la difusión del patrimonio arqueológico de Cataluña que se encuentra sumergido en aguas costeras e interiores.

\section{Antecedentes}

En 1894 unos buzos griegos, pescadores de esponjas, que habían dejado su país atraídos por el preciado coral rojo típico del cabo de Creus, fueron contratados por Romualdo Alfarás para extraer unas ánforas del fondo del mar. Lo que hace peculiar esta actuación es que Alfarás era corresponsal de la Asociación Artístico-Arqueológica Barcelonesa y que en el mismo año Alfarás publicó en el boletín de esa asociación un artículo en el que explicaba los trabajos realizados, los materiales recuperados y las motivaciones de todo ello, publicación que constituye una precursora memoria de excavación arqueológica subacuática.

Desgraciadamente este trabajo científico pionero no tuvo una continuación inmediata y fue necesario esperar varias décadas para que se llevaran a cabo otras actuaciones de este tipo que, como el primer trabajo, también fueron acciones puntuales fruto de algún hallazgo espectacular y del interés de alguna persona concreta. La recuperación del sarcófago de Hipólito en aguas de Tarragona en 1948 o la recuperación de ánforas en el pecio de Palamós a finales de los años cincuenta son algunas de las operaciones arqueológicas más conocidas.

La preparación del III Congreso Internacional de Arqueología Submarina, que se celebró en Barcelona en 1961, motivó a submarinistas y a arqueólogos a colaborar y una buena prueba de ello fueron los 23 yacimientos arqueológicos submarinos presentados al congreso. Pero, probablemente, el logro más importante de esta reunión fue el posibilitar que los submarinistas deportivos y los arqueólogos terrestres españoles entraran en contacto con la realidad científica internacional, tanto a nivel teórico como práctico, dado que la celebración del congreso motivó que se desplazara la nave Daino del Centro Sperimentale di Archeologia Sottomarina y que se realizaran algunas prospecciones arqueológicas en la costa catalana.

Desgraciadamente, los votos consensuados y recogidos en las actas del congreso, y que en su día se hicieron llegar a las autoridades competentes, en el sentido de recomendar la creación en España de un Centro Experimental de Arqueología Submarina y de armar una embarcación para este fin, tardarían todavía décadas en encontrar una respuesta positiva. Pero se había iniciado un camino.

Sin duda, la creación, a partir de 1969, de los llamados Patronatos de Arqueología Submarina, es una consecuencia de aquel congreso. Al menos lo fue la creación en 1972 del patronato de Gerona impulsado por Miguel Oliva y Federico Foerster, que habían tenido una presencia relevante en el congreso de Barcelona. Otros que nacen por esas fechas son los de Baleares, Cartagena y Ceuta.

El Patronato de Arqueología Submarina de la Provincia Marítima de Gerona se creó por decreto 2588/1972 y se le encomendó:

a) Velar por el cumplimiento de las leyes y reglamentos de excavaciones arqueológicas dentro de la zona costera.

b) Promover la realización de exploraciones y excavaciones arqueológicas submarinas en las costas y playas de Gerona.

c) Coordinar las distintas actividades que en esta materia se realicen por organismos públicos, entidades oficiales o particulares.

d) Denunciar a las autoridades correspondientes las infracciones de que tenga noticia y se cometan en materia de excavaciones arqueológicas submarinas dentro de la indicada zona costera.

e) Promover cuantas iniciativas y planes tiendan a incrementar y poner orden en las excavaciones arqueológicas submarinas que se realicen en las costas de la provincia de Gerona

Este patronato, que realizó una actividad voluntaria y muy meritoria, nunca contó con arqueólogos capacitados para hacer inmersión subacuática y, de hecho, no tuvo ninguno a partir del fallecimiento en 1974 del doctor Oliva, que participaba en el patronato en su calidad de Consejero Provincial de Bellas Artes.

En el decreto de fundación se contemplaba que todos los cargos serían honoríicos y gratuitos, y así era el cargo de Federico Foerster, que procedente del buceo deportivo se convirtió, con una dedicación ejemplar, en el técnico de trabajos arqueológicos subacuáticos del patronato, durante el tiempo que le dejaban libre sus obligaciones laborales.

La Diputación de Gerona acogió al patronato bajo la tutela de su Servicio Técnico de Investigaciones Arqueológicas del que el doctor Oliva era director.

Paralelamente a estos hechos se estaba produciendo otro, que potenciaba el nacimiento de la arqueología subacuática, pero que acabaría convirtiéndose en un serio problema. En 1942 la invención del regulador Cousteau-Gagnan abrió progresivamente las puertas del fondo del mar al gran público. En 1954 se creó en Barcelona el Centro de Recuperaciones e Investigaciones Submarinas, el primer club de inmersión subacuática, tras el que han ido llegando otros muchos. También supuso una creciente afluencia de turistas, especialmente intensa en la Costa Brava a partir de los años setenta, atraídos por la belleza de los fondos marinos y la claridad y la temperatura de las aguas.

Los submarinistas de los años sesenta y setenta fueron auténticos descubridores de un mundo nuevo que, desde el punto de vista arqueológico, había permanecido 
inalterados desde la prehistoria. No todos fueron conscientes de la necesidad de conservar ese nuevo mundo y es terrible escuchar relatos sobre barcos romanos o griegos intactos que desaparecieron en pocos días.

Lo cierto es que, cuando se pudo realizar la catalogación del patrimonio arqueológico submarino de Cataluña, se comprobó que el cien por ciento de los yacimientos descubiertos con anterioridad a 1980 estaba expoliado y que un ochenta por ciento de estos había perdido todo o prácticamente todo su valor como documentos históricos. Un trabajo periodístico evaluó en más de 5.000.000.000 ptas. de 1980 el valor en el mercado negro de todo el material arqueológico extraído durante veinticinco años, únicamente en la Costa Brava, una zona costera de algo más de cien kilómetros de longitud.

En 1981 la Diputación de Gerona fue sensible a esta problemática y decidió extender, también al mar, las actuaciones que hasta ese momento venía realizando su Servicio Técnico de Investigaciones Arqueológicas. Para ello creó un departamento específicamente dedicado a la arqueología subacuática. Este hecho era un punto de inflexión en la trayectoria seguida hasta entonces por la arqueología subacuática, ya que, por primera vez, una administración pública contrataba personal para ocuparse de este patrimonio; creaba una partida presupuestaria con esta finalidad; $y$ al menos administrativamente la arqueología subacuática comenzaba a tener un tratamiento similar al de la arqueología terrestre.

Otro hito, todavía más importante, lo constituyó, pocos años después, en 1985, la promulgación de la ley 16/1985 del Patrimonio Histórico Español, por la que se concedía el mismo tratamiento legal a los restos arqueológicos terrestres y subacuáticos.

Fueron estos unos años de especial efervescencia político-administrativa en los que se definió y materializó el traspaso de competencias a las comunidades autónomas y se organizó cada una de ellas. Cataluña asumió sus competencias sobre arqueología, y entre ellas las referentes a arqueología subacuática, a pesar de las reticencias de algunos, que argumentaban, sin fundamento, que esta actividad al desarrollarse en el mar territorial no era competencia de las comunidades autónomas.

\section{El Centre d'Arqueologia Subaquàtica de Catalunya (CASC)}

La asunción de competencias por parte del Departament de Cultura supuso, de hecho, que el pequeño núcleo de arqueología subacuática existente en la provincia de Gerona, y dependiente de la Diputación, asumiera la problemática o como mínimo las urgencias de toda Cataluña. No obstante, no fue hasta 1992 cuando la situación se oficializó con la creación del CASC, ya directamente dependiente del Departamento de Cultura, el cual dotó al núcleo de Gerona de personal, una embarcación y más infraestructuras.
EI CASC se situó orgánicamente como una sección del Servei d'Arqueologia, de tal modo que el organismo responsable de la arqueología catalana lo era tanto del ámbito terrestre como del acuático. En 1996 se produjo el traspaso de este centro al Museu d'Arqueologia de Catalunya, un organismo autónomo en donde el CASC, además de disponer de un mayor presupuesto, se beneficia de un modelo de gestión administrativa más desconcentrada.

Se dan en este planteamiento dos matices peculiares y diferenciadores de la tradición europea en este campo:

- La arqueología subacuática no se estructura como una actividad independiente de la arqueología terrestre; todo lo contrario, se potencia una íntima colaboración. A esta filosofía responde el hecho de que en el momento de dotar al CASC de una sede se decida construir un edificio que albergue tanto a la arqueología terrestre como a la subacuática.

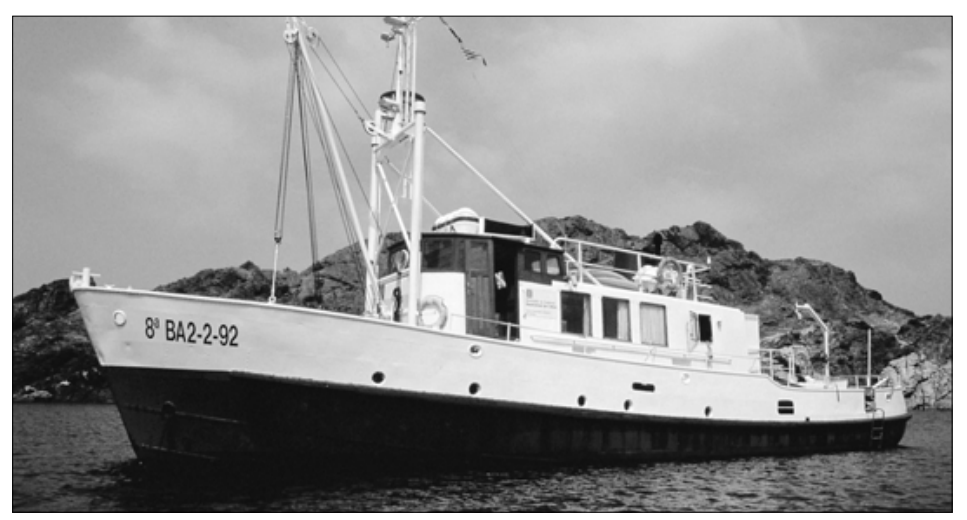

- Se entiende la arqueología subacuática no como una actividad exclusivamente relacionada con el mar, la navegación y los barcos, sino como una actuación sobre el patrimonio cultural sumergido, o sería más propio decir sobre el patrimonio cultural húmedo. Se generan así dos tipos de actividad: por una parte, aquella que podríamos llamar con toda propiedad arqueología subacuática, y que tiene una connotación técnica relacionada con la problemática que presenta la excavación, conservación y restauración del patrimonio cultural que puede encontrarse en el mar, en un río, en un pozo o en una capa freática y otra actividad que denominamos arqueología náutica, que tiene una connotación científica relacionada con la investigación del comercio, el tráfico, la navegación y la arquitectura naval.

En este sentido encontramos especialmente apropiado el nombre de Centro Nacional de Arqueología Náutica e Subaquática que se dio en Portugal al organismo responsable de este tipo de actividad.

Pero las cuestiones técnicas van más allá de la mera excavación. Una peculiaridad del medio acuático es el especial estado de conservación de los materiales arqueológicos que contiene. Esto, que es evidente para los materiales de naturaleza orgánica, especialmente maderas, cueros, tejidos, cestería, lo es también para
El barco Thetis dedicado a arqueología subacuática 


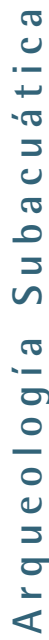

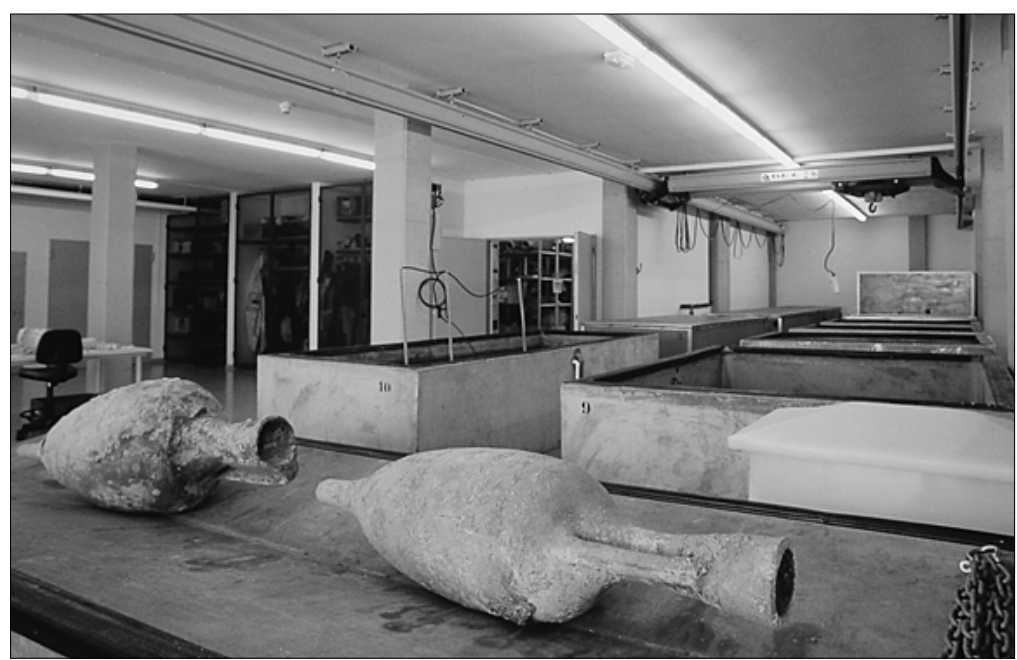

Detalle del laboratorio de restauración del CASC. En

un plano intermedio, los

depósitos de desalado y electrolisis. Al fondo, depósitos términos para impregnación con "PEG". los objetos metálicos o cerámicos y en general para los de cualquier tipo. Es por esta razón que los diversos centros de arqueología subacuática dedican una atención especial a sus laboratorios de conservación para poder solucionar una problemática que les es específica.

Se configura así el CASC como un organismo técnico que aporta personal, infraestructura y conocimientos especializados para colaborar en actuaciones en yacimientos terrestres con presencia de agua. También es un organismo de soporte de aquellos equipos de trabajo de universidades u otros centros que desarrollen su propio proyecto de investigación de arqueología náutica. Es también el CASC un organismo de gestión y un centro de investigación del patrimonio cultural subacuático de Cataluña.

Todo lo anterior obliga a disponer de: un deposito centralizado de maquinas, instrumentos, equipos y herramientas adecuados; un laboratorio especializado en restauración y conservación de materiales arqueológicos húmedos, especialmente en aquellos de naturaleza orgánica; una biblioteca especializada.

Con estos medios el CASC realiza dos tipos de trabajos: Gestión del patrimonio cultural subacuático de Cataluña e investigación científica de este patrimonio.

\section{La gestión y la investigación del patrimonio}

La compra en 1992 del barco Thetis dio movilidad al equipo de trabajo y permitió dar nuevos ímpetus a la labor de inventario de los yacimientos, trabajo que ya se había iniciado en 198 I con escasos medios. Creemos que un inventario lo más completo posible de los yacimientos, sus características y estado de conservación, es una herramienta imprescindible para posteriormente poder elaborar un programa de actuaciones.

Este proyecto se planteó para ser realizado en cuatro años durante los que poder cubrir los $550 \mathrm{Km}$. de costa. Un trabajo previo de documentación, seguido por unos contactos personales con los pescadores, submarinistas, museos locales, etc. permitió acotar áreas de actuación en las que posteriormente, con la ayuda de la embarcación Thetis, se pudieron hacer comprobaciones y sondeos submarinos. Este trabajo permitió pasar de los 175 yacimientos conocidos a finales de 1991, a los 730 inventariados al finalizar el proyecto.

Esta carta arqueológica se convirtió en la herramienta que permitió programar las actuaciones de los años siguientes:

- Actuaciones de urgencia.- En aquellos yacimientos con riesgo de deterioro debido a causas naturales, como la erosión, o antrópicas.

- Arqueología preventiva.- En aquellos lugares que quedarían afectados por obras públicas, especialmente construcción de puertos o regeneración de playas.

- Investigación.- La carta arqueológica permitió detectar aquellos yacimientos más rentables desde el punto de vista científico.

No siempre ha sido posible llevar a la práctica este planteamiento teórico de la forma deseada y esto debido a numerosas razones: la compleja legislación y el reparto de competencias sobre el mar y la costa entre organismos muy diversos de la administración central y autonómica; la falta de hábitos y de experiencia en este campo; la falta de medios económicos

Más fácil, desde el punto de vista administrativo, es la investigación programada sobre un yacimiento concreto ya que se ve liberada de la presión que supone la premura de tiempo que en general imponen las actuaciones de urgencia o las preventivas y porque permite adaptar los objetivos a los recursos disponibles.

Esta investigación se lleva a cabo o bien directamente por el CASC siguiendo un proyecto propio y, con sus propios medios, o con la colaboración de instituciones externas o bien participando en proyectos de otras instituciones. En este sentido es especialmente deseable la participación de universidades ya que facilita la incorporación de estudiantes universitarios y de esta manera se posibilita la formación de nuevos técnicos en arqueología subacuática o arqueología náutica.

Una correcta actuación sobre el patrimonio requiere, entre otros componentes, técnicos cualificados y que tendrán de conocer desde los principios físicos de la disolución de los gases en los líquidos, hasta las teorías sobre los cambios en la economía precapitalista, pasando por el funcionamiento de la motobomba que acciona una manga de succión o los principios metodológicos de una excavación subacuática. Ninguna universidad española forma a este tipo de arqueólogo. En la Universidad de Barcelona la reciente inclusión en el programa docente de una asignatura teórica cuatrimestral con el título de Arqueología Náutica y Subacuática, que se completa con unas prácticas en el CASC, en un tímido intento. Este es un problema pendiente de solución y universidades como la de Murcia, Valencia, Zaragoza, 
entre otras, intentan solucionarlo con cursos de verano, jornadas o asignaturas de tercer ciclo.

\section{La difusión}

Basta una ojeada a los museos de arqueología para comprobar el escaso interés que tradicionalmente ha existido por el tráfico naval. En nuestros museos generalmente se exponen materiales procedentes de centros de producción o de centros de consumo, olvidando los condicionantes que impone el transporte, el tercer elemento necesario para estudiar y entender un proceso económico en su globalidad.

La arqueología náutica, que casi nos atreveríamos a llamarla arqueología del transporte marítimo, enlaza estrechamente con la arqueología terrestre y es con esta concepción que podremos dejar de hablar de arqueología terrestre y de arqueología subacuática para hablar únicamente de arqueología. Es cierto que en sus objetivos nada diferencia a ambas arqueologías, pero también es cierto que la arqueología náutica hace surgir campos de investigación que le son propios.

EI CASC desde sus orígenes desplegó dos tipos de estrategias de difusión: una prioritaria dirigida al gran público y también otra dirigida al colectivo de técnicos y responsables del patrimonio cultural, formado exclusivamente por personas habituadas a trabajar con patrimonio terrestre y sobre los que todavía pesaban viejos tópicos, como el de que la arqueología subacuática era una actividad de buceadores deportivos, que sacaban ánforas del fondo del mar para llevarlas a un museo. Todos hemos sufrido la broma de asimilar la arqueología subacuática a vacaciones, sol y playa.

Sólo la sólida formación de los arqueólogos subacuáticos y las publicaciones científicas de los trabajos realizados por parte de unos; y la generosidad, por parte de otros para apoyar una actividad que, por estar naciendo, necesita ayuda, podrá producir una visión más completa y exacta de nuestro pasado histórico.

El CASC en estos momentos ha publicado monografías de los yacimientos excavados: dos barcos medievales (Culip VI y Canal Olímpico), una nave romana (Culip IV) y un poblado lacustre neolítico (La Draga). Los temas publicados no son casuales: abarcan un amplio periodo cronológico y contemplan yacimientos de transporte y de hábitat, ofreciendo así informaciones complementarias a un amplio espectro de la comunidad científica.

Una colección de videos (Imágenes de Arqueología Subacuática), publicaciones de divulgación, conferencias, dos talleres para escolares (Así era un barco romano e Historia bajo el agua), exposiciones temporales y la apertura el último verano del primer parque arqueológico subacuático de España (Zambullida al pasado. Descubrir la Ampurias submarina) son algunas de las actividades destinadas al gran público. Esta última, planificada con cierto temor e inaugurada co-

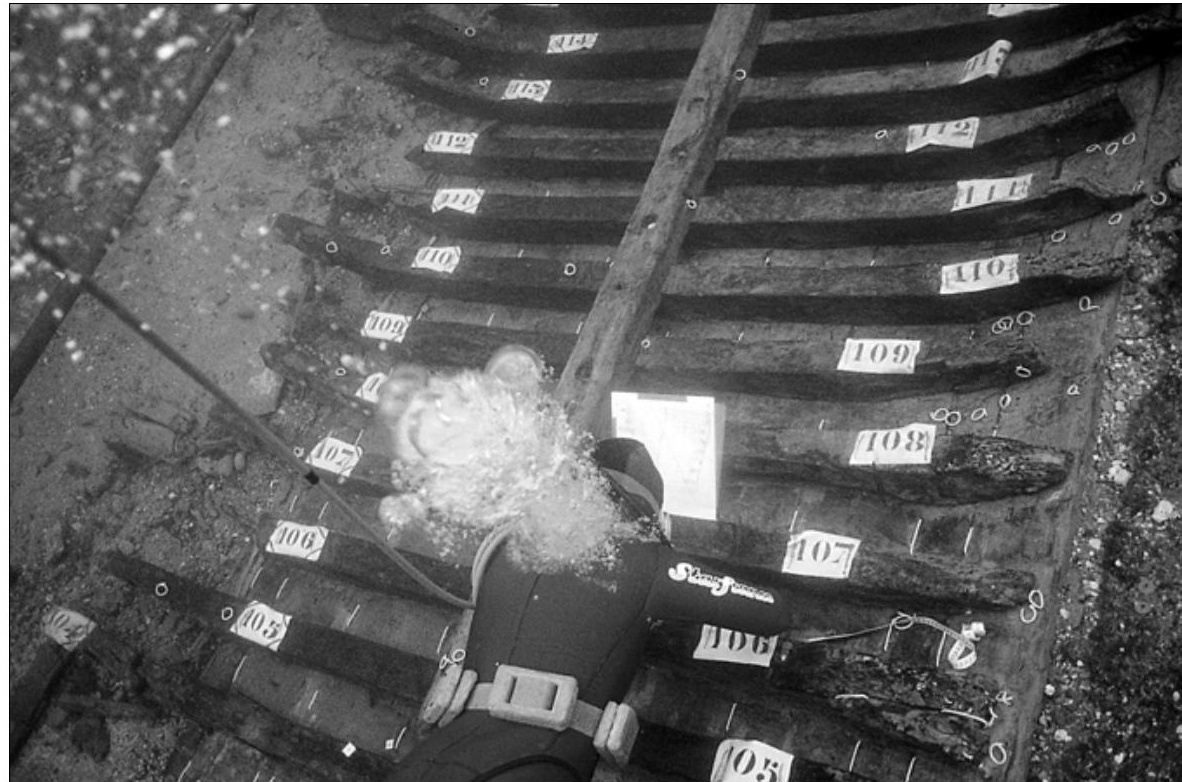

mo experiencia piloto, ha resultado enormemente gratificante para organizadores y participantes. Dos monitores en un centro de interpretación, sobre la misma playa de Ampurias, reciben a los participante y tras una explicación sobre la actividad náutica de los ampuritanos, proporcionan a los visitantes unas gafas, un tubo y unas aletas para ver bajo el agua y facilitar la natación. Un cinturón flotador completa el equipo. El grupo, acompañado por los monitores, realiza un recorrido, marcado por boyas, en una zona donde la profundidad oscila entre 0 y 2 metros y donde los participantes pueden ver los cientos de bloques de piedra que formaban uno de los diques del puerto de la ciudad, una columna y varias reproducciones de ánforas que intentan simular el cargamento de una nave.

Un elemento fundamental para la difusión debería ser el museo. Cataluña no dispone de un museo de arqueología subacuática que, de existir, debería llamarse de otra manera. Pero la primera cuestión a dilucidar es si debe existir o no un museo de este tipo. Si defendemos la unidad de la arqueología terrestre y subacuática sería ilógico defender la existencia de un museo para la arqueología en tierra y otro para la arqueología en el agua. Para algunos la solución idónea podría ser aquel museo que contemplara la actividad humana pretérita en su globalidad y explicara por ejemplo cómo y por qué las ánforas fabricadas en el valle del Guadalquivir, para exportar el aceite andaluz durante el siglo II d.C., aparecen, por ejemplo, en un poblado indígena de los Alpes, después de varios itinerarios marítimos, fluviales y terrestres. Normalmente este tipo de museo, en el que junto a los restos de un horno se exponga la arquitectura de un barco, no existe y algunos opinarán que no es conveniente ni necesario que exista.

Por otra parte, es cierto que la arqueología subacuática todavía esta rodeada de un cierto mito y existe una demanda social creciente sobre museos monográficos de este tema. También es cierto que la exposición de barcos originales requieren unas condiciones
El estudio de la arquitectura naval es un campo de investigación que se posibilita con la arqueología subacuática. Culip VI, s. XIV d. C. 

ques arqueológicos subacuáticos es una posibilidad para la difusión del patrimonio cultural subacuático (Ampurias, puerto romano, año 200) arquitectónicas y medioambientales que en genera no reúnen los museos arqueológicos tradicionales.

Es un problema complejo y además no podemos olvidar la realidad de aquellas instituciones que tradicionalmente se conocen como museos marítimos. Ahora el desarrollo de la arqueología subacuática viene a construir puentes, cada vez más amplios, entre los museos del mar y los arqueológicos

\section{Protección y conservación}

Otra de las misiones encomendadas al CASC en el decreto de creación es la protección y conservación del patrimonio cultural subacuático.

Se han llevado a termino tres acciones judiciales, de las que dos acabaron con sobreseimiento del caso y otra en una condena.

Lo que es evidente es que las medidas policiales, por si solas, no son la solución al grave problema del expolio, que mucho más intenso en el agua que en tierra.

Durante los últimos años se ha dado en España un paso de gigante en este tema. La existencia de centros de arqueología subacuática en Andalucía, Murcia (centro nacional dependiente del ministerio), Valencia y Cataluña hace que toda la costa entre Gerona y Huelva disponga de personal y medios, aunque limitados, especializados en este patrimonio. La existencia de estos centros ya ha producido una disminución de la destrucción, entre otras razones porque se ha valorado este patrimonio a los ojos de las numerosas personas que actuaban por ignorancia y porque permite emprender medidas preventivas.

El camino a recorrer no es fácil. La atávica creencia de que lo que hay en el mar es para el que lo encuentra es un serio inconveniente. La dificultad para detectar o evitar un acto de expolio en el mar es otro, pero la situación es muy diferente a la de hace solamente dos décadas, cuando a casi nadie le importaba lo que pasaba con este patrimonio. La sensibilidad social hacia la protección va en aumento y dependerá de los medios disponibles y de la habilidad de los responsables de este patrimonio el que siga creciendo, mediante una correcta estrategia de difusión que permita poner de manifiesto los beneficios sociales que aporta la conservación de este patrimonio. Siempre quedarán los recalcitrantes pero las legislaciones estatales y autonómicas ya existen.

Se presenta aquí un campo abierto a la discusión sobre si la ley 16/1985 sobre el Patrimonio Histórico Español y las autonómicas que la siguieron son adecuadas o no para la correcta conservación del patrimonio cultural subacuático.

Es cierto que esta legislación ofrece el mismo nivel de protección a los restos arqueológicos terrestres y a los subacuáticos, pero se olvidó que estos restos, por las características del medio que los contiene y por la diferencia de los conjuntos legales de ambos medios, presentan una problemática, en ocasiones, totalmente diferente. Sería conveniente que, como ocurre en otros países de nuestro entorno cultural, existiera una legislación específica sobre este tipo de patrimonio. Nada tienen que ver las legislaciones sobre el suelo y urbanismo con las leyes de costas, de puertos y del mar en general, marcos en los que se mueven unas $y$ otras actuaciones arqueológicas.

La legislación catalana establece escasas diferencias entre los restos arqueológicos terrestres y subacuáticos, pero hay una que merece ser resaltada en cuanto que no se contemplaba en la legislación estatal y que se ha mostrado de gran utilidad. Mientras para los hallazgos casuales efectuados en tierra se establece un término para entregar el objeto arqueológico a la administración competente, para este mismo tipo de hallazgo efectuado en el medio acuático se regula que el objeto no puede desplazarse de su lugar de hallazgo y aquello que ha de notificarse es su ubicación. La medida pretende evitar el deterioro que sufren las maderas de los barcos y en general todos los objetos que padecen un brutal cambio al pasar del medio acuático al aéreo y por otra parte pretende evitar la picaresca en ocasiones utilizada por los submarinistas que eran sorprendidos con un ánfora en la barca a su llegada al puerto.

La arqueología subacuática es una actividad joven que evoluciona a un ritmo acelerado, pero serán necesarios algunos años para que alcance su nivel de normalidad. Mientras tanto, en ocasiones, chirrían sus relaciones con la arqueología terrestre, nada grave. Debe encontrar su puesto en los organigramas de los organismos administrativos y debe ganarse el nivel que merece en las aulas universitarias. Mientras tanto la falta de personal es el déficit más evidente y esto es patente, no únicamente en cuanto a profesionales de la arqueología, sino también en cuanto al resto de técnicos necesarios, restauradores, especialistas en topografía subacuática, ingenieros navales conocedores de la problemática de las embarcaciones antiguas, fotógrafos y es que no podemos olvidar que si es cierto que la arqueología es una actividad pluridisciplinaria, lo es todavía más en arqueología subacuática. 